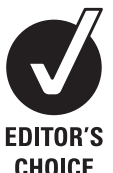

CHOICE
${ }^{1}$ Cardiology Department 'Morgagni-Pierantoni' Hospital, Forli, Italy

${ }^{2}$ Cardiology Institute, Catholic University of Sacred Heart, Rome, Italy

${ }^{3}$ Department of Cardiology, Jagiellonian University, Kracow, Poland

${ }^{4}$ Institut Cardiovasculaire Paris Sud, Massy, France

${ }^{5}$ Division of Cardiology, University of Turin, Turin, Italy

\section{Correspondence to} Dr M De Vita, Cardiology Department 'MorgagniPierantoni' Hospital, Via Porta Merlonia, 2, 47100 Forlì (FC), Italy; mariarosariadevita77@libero.it

Accepted 6 April 2010

\title{
Thrombus aspiration in ST elevation myocardial infarction: comparative efficacy in patients treated early and late after onset of symptoms
}

\author{
Maria De Vita, ${ }^{1}$ Francesco Burzotta, ${ }^{2}$ Italo Porto, ${ }^{2}$ Dariusz Dudek, ${ }^{3}$ Thierry Lefèvre, ${ }^{4}$ \\ Carlo Trani, ${ }^{2}$ Waldemar Mielecki, ${ }^{3}$ Giampaolo Niccoli, ${ }^{2}$ Giuseppe G L Biondi-Zoccai, ${ }^{5}$ \\ Filippo Crea $^{2}$
}

\begin{abstract}
Background Restoration of myocardial perfusion is the goal of percutaneous coronary intervention (PCI) in patients with ST elevation myocardial infarction. A major predictor of no-reflow is the increasing time to treatment (TTT). Thrombus aspiration (TA) is reported to improve myocardial reperfusion as compared with standard PCI (SP).

Objective To investigate the influence of $\Pi \Pi$ on TA efficacy.

Design Pooled analysis of individual patients' data of three prospective randomised trials comparing TA and SP.
\end{abstract}

Patients A total of 299 patients (150 in TA group and 149 in SP group) entered the study. The study population was divided into three subgroups according to the $\Pi \pi$ : $\leq 3 \mathrm{~h}$ (short $\Pi$ T subgroup), $>3 \mathrm{~h}$ to $\leq 6 \mathrm{~h}$ (intermediate $\Pi \pi$ subgroup), $>6 \mathrm{~h}$ to $\leq 12 \mathrm{~h}$ (long $\Pi \mathrm{T}$ subgroup).

Main outcome measures The goal of the study was the comparison of optimal myocardial reperfusion, defined as the combination of myocardial blush grade 2 or 3 at post-PCl angiography and ST resolution more than $70 \%$ at post-PCl ECG, between SP and TA according to TT.

Results In the SP group, increasing ПT was associated with a decreased rate of optimal reperfusion $(27.4 \%$ vs $17.9 \%$ vs $10 \%$, p for trend $=0.06$ ), whereas in the TA group the same trend was not seen $(40.9 \%$ vs $33.8 \%$ vs $50 \%$, p for trend $=0.93$ ). In a multivariate logistic regression model, a significant interaction $(p=0.04)$ between time to treatment and thrombus aspiration was observed.

Conclusions TA limits the adverse effects of TT prolongation on myocardial reperfusion.

\section{BACKGROUND}

No-reflow is a common adverse event affecting the long-term outcome of patients with acute myocardial infarction undergoing urgent percutaneous interventions (PCI).$^{1-4}$ Atherothrombotic embolisation is considered to have an important role in the pathogenesis of this multifactorial phenomenon. ${ }^{4}$ The use of thrombus-aspiration devices is associated with a significant reduction of distal embolisation and of no-reflow during primary or rescue $\mathrm{PCI}^{5}$ and seems to favourably influence clinical outcome. ${ }^{6}$

Besides atherothrombotic embolisation, another important independent predictor of myocardial reperfusion and long-term clinical outcome in patients with ST elevation myocardial infarction (STEMI) undergoing mechanical reperfusion is time to treatment (TTT). Indeed, experimental studies have shown that the extent of myocardial and microvascular injury is strongly dependent on the duration of ischaemia, with reduced salvage of myocardium when reperfusion is accomplished after $3 \mathrm{~h}$ of coronary occlusion. ${ }^{8-10}$ Accordingly, prolonged ischaemic time is associated with lower rates of ST resolution (STR) and myocardial blush grade (MBG) 2-3, with larger infarct size and higher 1-year mortality in patients with STEMI. ${ }^{11} 12$

Few and conflicting data are available on the possible interaction between TTT and thrombus aspiration use in patients with STEMI undergoing mechanical reperfusion. ${ }^{13} 14$

We assessed this interaction by pooling the clinical and angiographic data from three randomised trials comparing manual thrombus aspiration (TA) and standard PCI (SP).

\section{METHODS}

We pooled the single patients' baseline and postPCI clinical and angiographic data from three randomised trials comparing TA with SP in patients with STEMI. The trials included were the REMEDIA trial, ${ }^{15}$ the PIHRATE trial ${ }^{16}$ and the Export study by Noel et al. ${ }^{17}$ The key protocol characteristics of the three randomised studies are summarised in table 1.

The whole study population was analysed according to the TTT (time from symptom onset to catheter laboratory), which was categorised as $\leq 3 \mathrm{~h}$ (short TTT subgroup), $>3 \mathrm{~h}$ to $\leq 6 \mathrm{~h}$ (intermediate TTT subgroup) and $>6 \mathrm{~h}$ to $\leq 12 \mathrm{~h}$ (long TTT subgroup)

Baseline and post-PCI measures of coronary flow, thrombus score and MBG were derived from the original studies and were obtained in all three trials according to the following standard methods:

- Anterograde coronary flow according to the standard TIMI criteria ${ }^{18}$;

- Thrombus score according to the TIMI study group $^{19}$;

- MBG according to van't Hof et al. ${ }^{20}$

STR was defined as $\geq 70 \%$ reduction in the sum of the ST-segment elevation score between ECGs obtained before PCI and immediately after the procedure in all the three randomised trials ${ }^{21}$ and the STR analysis derived from the original studies.

Patient-level data on the occurrence of death, new myocardial infarction and target vessel revascularisation (early major adverse coronary events (MACE)) during hospitalisation were also obtained from the original studies. 
Table 1 Key features of the three trials entered in the study

\begin{tabular}{|c|c|c|c|c|c|c|c|c|}
\hline \multirow[b]{2}{*}{ Trial } & \multirow[b]{2}{*}{ Design } & \multirow{2}{*}{$\begin{array}{l}\text { Type of TA } \\
\text { device }\end{array}$} & \multirow[b]{2}{*}{ Timing of randomisation } & \multirow{2}{*}{$\begin{array}{l}\text { Angiographic inclusion } \\
\text { criteria }\end{array}$} & \multirow[b]{2}{*}{ Exclusion criteria } & \multicolumn{2}{|c|}{$\begin{array}{l}\text { Number } \\
\text { of patients }\end{array}$} & \multirow{2}{*}{$\begin{array}{l}\text { Stenting } \\
\text { rate }(\%)\end{array}$} \\
\hline & & & & & & $\overline{\mathbf{S P}}$ & $\overline{T A}$ & \\
\hline REMEDIA $^{15}$ & Single centre & Diver CE & Before coronary angiography & None & Ischaemic time $>12 \mathrm{~h}$ & 49 & 50 & 100 \\
\hline Noel et $a l^{17}$ & Single centre & Export & After coronary angiography & Baseline TIMI flow $<3$ & Ischaemic time $>12 \mathrm{~h}$ & 26 & 24 & 100 \\
\hline PIHRATE $^{16}$ & Multicentre & Diver CE & After coronary angiography & Baseline TIMI flow 0-1 & $\begin{array}{l}\text { Ischaemic time }>6 \mathrm{~h} \text { ST } \\
\text { elevation }>3 \mathrm{~mm} \text { in one lead }\end{array}$ & 96 & 100 & 98 \\
\hline
\end{tabular}

$\mathrm{SP}$, standard $\mathrm{PCl} ; \mathrm{TA}$, thrombus aspiration; MI.

\section{Goals of the study}

The main goal of the study was to compare optimal myocardial reperfusion (defined as final MBG $2-3$ plus STR $\geq 70 \%{ }^{22}$ between patients randomised to TA or SP in the three TTT subgroups).

We also compared STR $\geq 70 \%$, final TIMI 3 flow, final MBG 2-3 and in-hospital MACE between patients randomised to TA or SP in the three TTT subgroups.

\section{Statistical analysis}

Continuous variables (presented as mean \pm SD) were compared by $t$ test and analysis of variance. Categorical variables (reported as raw numbers (\%)) were compared with Fisher exact tests. Trends in proportions were assessed with a linear-by-linear association test.

A multivariate logistic regression model was fitted to examine interaction between TTT and TA. All the predictors of optimal reperfusion at univariate analysis with $\mathrm{p}<0.1$ (diabetes, left anterior descending artery as infarct-related artery, thrombus score), plus background variables (age, sex, and a three-level variable representing the pooled studies), and TA, TTT and their interaction term, were included in the model.

\section{RESULTS}

A total of 345 patients were enrolled in the three trials. Forty-six patients were excluded from the study as assessment of final MBG was not possible for technical reasons and/or early postPCI ECG was lacking or non-interpretable. Thus, 299 patients entered the study: 150 patients randomised to TA and 149 patients randomised to SP. As shown in table 2, the baseline clinical and angiographic characteristics of patients randomised to TA or SP were similar.

Overall, patients randomised to TA had significantly better rates of early STR $\geq 70 \%(p=0.01)$, final TIMI 3 flow $(p=0.02)$, final MBG 2-3 ( $\mathrm{p}=0.001)$ and optimal myocardial reperfusion

Table 2 Baseline clinical and angiographic features of the study population according to treatment

\begin{tabular}{llll}
\hline & TA (N=150) & SP (N=149) & $\mathbf{p}$ \\
\hline Age (mean \pm SD) & $60 \pm 11$ & $60 \pm 10$ & 0.77 \\
Sex (M), n (\%) & $125(83)$ & $113(76)$ & 0.11 \\
Diabetes, n (\%) & $24(16)$ & $19(13)$ & 0.42 \\
Failed TL, n (\%) & $21(14)$ & $21(14)$ & 0.98 \\
Ilb/llla inhibitors, n (\%) & $70(47)$ & $67(45)$ & 0.76 \\
Time to treatment (min) (mean \pm SD) & $220 \pm 125$ & $246 \pm 173$ & 0.12 \\
MVD, n (\%) & $65(43)$ & $51(34)$ & 0.11 \\
LAD as infarct related artery, n (\%) & $61(41)$ & $69(46)$ & 0.32 \\
Baseline TIMl flow 0-1, n (\%) & $132(88)$ & $131(88)$ & 0.98 \\
Baseline TS 3-5, n (\%) & $100(67)$ & $85(57)$ & 0.09 \\
RVD (mm) (mean \pm SD) & $3.19 \pm 0.44$ & $3.13 \pm 0.44$ & 0.18 \\
Lesion length (mm) (mean \pm SD) & $21.85 \pm 9.69$ & $21.42 \pm 8.40$ & 0.68
\end{tabular}

$L A D$, left anterior descending artery; MVD, multivessel disease; RVD, reference vessel diameter; $\mathrm{SP}$, standard $\mathrm{PCl}$; TA, thrombus aspiration; TL, thrombolysis; TS, thrombus score. $(p<0.001)$ than patients randomised to SP, while in-hospital MACE rates were similar $(p=0.21)$ (table 3$)$.

The study population was divided according to the TTT into three subgroups as follows:

1. short TTT subgroup: 128 patients (66 TA vs 62 SP)

2. intermediate TTT subgroup: 135 patients (68 TA vs 67 SP)

3. long TTT subgroup: 36 patients (16 TA vs 20 SP).

There were no significant differences in baseline clinical and angiographic characteristics between the three precoronary time subgroups (table 4). In particular, there were no differences in the rate of baseline TIMI flow $0-1$ and in the rate of baseline thrombus score 3-5.

In the short TTT subgroup there was a trend in favour of TA for optimal reperfusion rate $(27 / 66$ (41\%) TA versus $17 / 62(27 \%)$ SP; $p=0.10$ ), while a significant advantage in favour of TA was observed in the intermediate TTT subgroup (23/68 (34\%) TA versus $12 / 67(18 \%) \mathrm{SP} ; \mathrm{p}=0.03)$ and in the long TTT subgroup (8/16 (50\%) TA versus $2 / 20(10 \%) \mathrm{SP} ; \mathrm{p}<0.001)$ (figure 1 ).

Moreover, in the SP group increasing TTTwas associated with a decreasing rate of optimal reperfusion $(27.4 \%$ vs $17.9 \%$ vs $10 \%$, $\mathrm{p}$ for trend=0.06), whereas in the TA group no trend was observed ( $40.9 \%$ vs $33.8 \%$ vs $50 \%$, p for trend=0.93) (figure 1 ).

The remaining angiographic, electrocardiographic and clinical finding according to treatment modality and TTT are shown in table 5

The clinical and angiographic predictors of optimal myocardial reperfusion in the whole population were identified by univariate analysis (table 6) and included (with background variables and the interaction term between TA and TTT) in the multivariate analysis, for which results are depicted in the table 7 . Moreover, at multivariate analysis, a significant interaction between thrombus aspiration and time to treatment was found $(p=0.04)$.

\section{DISCUSSION}

The results of this pooled analysis of three trials indicate that TA may counterbalance the adverse effects of increasing ischaemic time on myocardial reperfusion.

The failure to achieve myocardial tissue reperfusion is the main complication limiting the early and long-term clinical benefit of mechanical reperfusion in patients with STEMI. ${ }^{4}$ Noreflow phenomenon is multifactorial and can be caused by the variable combination of different pathogenetic components like

Table 3 ECG and angiographic results and MACE according to treatment

\begin{tabular}{lccc}
\hline & TA (N=150) & SP(N=149) & p \\
\hline STR $\geq 70 \%, n(\%)$ & $63(42)$ & $42(28)$ & 0.01 \\
TIMI 3 flow, n (\%) & $131(87)$ & $115(77)$ & 0.02 \\
MBG 2-3, n (\%) & $121(81)$ & $95(64)$ & 0.001 \\
STR $\geq 70 \%+$ MBG 2-3, n (\%) & $58(39)$ & $31(21)$ & $<0.001$ \\
MACE IH, n (\%) & $3(2)$ & $5(3.3)$ & 0.21
\end{tabular}

$\mathrm{IH}$, in-hospital; MACE, major adverse cardiac events; MBG, myocardial blush grade; SP, standard PCI; STR, ST-segment resolution; TA, thrombus aspiration. 
Table 4 Baseline clinical and angiographic features according to timeto-treatment

\begin{tabular}{|c|c|c|c|c|}
\hline Time to treatment (h) & $<3 \mathrm{~h}$ & $\geq 3 \mathrm{~h}$ to $<6 \mathrm{~h}$ & $\geq 6 \mathrm{~h}$ to $<12 \mathrm{~h}$ & $\mathbf{p}$ \\
\hline Number of patients & 128 & 135 & 36 & \\
\hline Age $($ mean $\pm S D)$ & $60 \pm 10$ & $60 \pm 11$ & $60 \pm 14$ & 0.93 \\
\hline $\operatorname{Sex}(M), n(\%)$ & $109(85)$ & $102(76)$ & $27(75)$ & 0.11 \\
\hline Diabetes, n (\%) & $17(13)$ & $22(16)$ & $4(11)$ & 0.65 \\
\hline TL failed, $\mathrm{n}(\%)$ & $25(20)$ & $13(10)$ & $4(11)$ & 0.06 \\
\hline llb/llla inhibitors, $\mathrm{n}(\%)$ & $66(52)$ & $56(41)$ & $15(42)$ & 0.22 \\
\hline MVD, n (\%) & $48(38)$ & $54(40)$ & $14(39)$ & 0.91 \\
\hline LAD as infarct- related artery, $\mathrm{n}(\%)$ & $55(43)$ & $59(44)$ & $16(44)$ & 0.98 \\
\hline Baseline TIMI flow $0-1, \mathrm{n}(\%)$ & 112 (88) & $118(87)$ & $33(92)$ & 0.74 \\
\hline Baseline TS $3-5, n(\%)$ & $81(63)$ & $80(59)$ & $24(67)$ & 0.65 \\
\hline $\operatorname{RVD}(\mathrm{mm})($ mean $\pm \mathrm{SD})$ & $3.15 \pm 0.44$ & $3.16 \pm 0.45$ & $3.13 \pm 0.32$ & 0.64 \\
\hline Lesion length $(\mathrm{mm})($ mean $\pm S D)$ & $22.6 \pm 9.4$ & $20.6 \pm 9.3$ & $21.78 \pm 7.05$ & 0.23 \\
\hline
\end{tabular}

$L A D$, left anterior descending artery; MVD, multivessel disease; RVD, reference vessel diameter; TL, thrombolysis; TS, thrombus score.

distal atherothrombotic embolisation and ischaemic injury. ${ }^{4}$ Ischaemic injury is known to be strongly related to the ischaemic time: after prolonged ischaemia, morphological changes in endothelial cells, in myocardial cells and in the interstitial space can cause microvascular obstruction ${ }^{23-25}$ and a longer time to reperfusion is associated with a higher prevalence and extension of no-reflow. ${ }^{9}$

Among the different strategies to reduce distal embolisation, the use of TA is promising. ${ }^{72}$ Whether or not the efficacy of TA depends on the ischaemic time is unknown.

According to our results the beneficial effect on optimal myocardial reperfusion of TA seems to be more pronounced in the subgroups with a time to treatment $>3 \mathrm{~h}$. In particular, in the TA group the rates of optimal myocardial reperfusion were constant in the three subgroups of TTT while in the SP group increasing TTT (as expected) was associated with decreasing rates of optimal reperfusion. Such original observation is consistent with the recent results of the VAMPIRE trial, which showed a greater reperfusion and clinical benefit by thrombectomy in the subgroup of late-presenting $(6-24 \mathrm{~h})$ patients. ${ }^{13}$ Interestingly, the recently published update of the American College of Cardiology guidelines on STEMI treatment considers thrombus aspiration as a class IIa indication for PCI in STEMI, suggesting that it is reasonable to use it in patients with high thrombus burden and short ischaemic time. ${ }^{27}$ This study

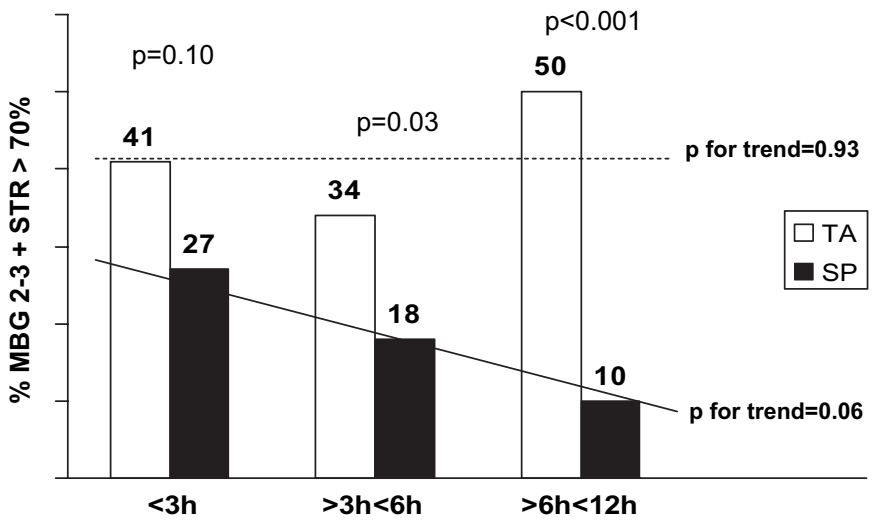

Figure 1 Rates of optimal myocardial reperfusion in the standard $\mathrm{PCl}$ (SP) and thrombus aspiration (TA) groups according to time to treatment. $p$ Value for comparison derived from $\chi^{2}$ test. Trend in proportions assessed with linear-by-linear association test. Continuous line for SP; dotted line for TA. MBG, myocardial blush grade; STR, ST resolution.
Table 5 ECG and angiographic results and in-hospital MACE according to treatment modality and to time to treatment

\begin{tabular}{|c|c|c|c|}
\hline Short TTT Subgroup ( $\mathrm{N}=128)$ & $T A(N=66)$ & $\mathrm{SP}(\mathrm{N}=62)$ & $\mathbf{p}$ \\
\hline $\mathrm{STR} \geq 70 \%, \mathrm{n}(\%)$ & $30(45)$ & $21(34)$ & 0.18 \\
\hline TIMI 3 flow, n (\%) & $59(89)$ & $52(84)$ & 0.35 \\
\hline MBG 2-3, n (\%) & $54(82)$ & $44(71)$ & 0.14 \\
\hline MACE IH, n (\%) & $1(1.5)$ & $1(1.6)$ & 0.50 \\
\hline Intermediate TTT Subgroup $(\mathrm{N}=135)$ & $T A(N=68)$ & $S P(N=67)$ & $\mathbf{p}$ \\
\hline STR $\geq 70 \%, \mathrm{n}(\%)$ & $25(37)$ & $17(25)$ & 0.15 \\
\hline TIMI 3 flow, n (\%) & $58(85)$ & $51(76)$ & 0.17 \\
\hline MBG $2-3, \mathrm{n}(\%)$ & $54(79)$ & $42(63)$ & 0.03 \\
\hline MACE IH n (\%) & $1(1.5)$ & $2(3.0)$ & 0.37 \\
\hline Late TTT Subgroup $(\mathrm{N}=36)$ & $\mathrm{TA}(\mathrm{N}=16)$ & $S P(N=20)$ & $\mathbf{p}$ \\
\hline STR $\geq 70 \%, \mathrm{n}(\%)$ & $8(50)$ & $4(20)$ & 0.01 \\
\hline TIMI 3 flow, n (\%) & $14(88)$ & $12(60)$ & 0.01 \\
\hline MBG $2-3, \mathrm{n}(\%)$ & $13(81)$ & $9(45)$ & 0.02 \\
\hline MACE IH, n (\%) & $1(6.3)$ & $2(10)$ & 0.42 \\
\hline
\end{tabular}

$\mathrm{IH}$, in-hospital; MACE, major adverse cardiac events; MBG, myocardial blush grade; SP, standard PCl; STR, ST-segment resolution; TA, thrombus aspiration.

showing greater absolute efficacy of TA with longer ischaemic time argues against this suggestion, leading to the need for further investigation on this crucial issue.

The most likely explanation of the increasing benefit of TA over time is that the contribution of distal embolisation to microvascular obstruction becomes more relevant with the passage of time. Unfortunately, this hypothesis cannot be tested in current experimental models, ${ }^{8-10}$ as in these models myocardial infarction is caused by coronary ligation and not by thrombotic occlusion.

The results of this pooled analysis of three randomised trials suggest that TA may reduce the adverse effect of the TTT prolongation on myocardial reperfusion in patients with STEMI

\section{Study limitations}

The main limitation of our study is the difference in the inclusion criteria used in the three trials which entered the singlepatient data analysis. This heterogeneity, leading to an overall lower rate of the primary end point in the PIHRATE trial, may be caused by the selection in this study of a higher-risk population, with baseline TIMI flow 0 or 1 , and the exclusion of lower-risk patients with largely patent culprit artery (TIMI flow

Table 6 Clinical and angiographic predictors of optimal myocardial reperfusion in the whole population

\begin{tabular}{llc}
\hline & OR (95\% Cl) & p \\
\hline Age & $0.97(0.95$ to 0.99$)$ & 0.07 \\
Sex (M) & $1.30(0.71$ to 2.50$)$ & 0.42 \\
STUDY variable & & 0.02 \\
EXPORT vs REMEDIA & $0.61(0.30$ to 1.24$)$ & 0.17 \\
PIHRATE vs REMEDIA & $0.47(0.26$ to 0.80$)$ & 0.007 \\
Diabetes & $0.40(0.18$ to 0.96$)$ & 0.03 \\
IIb/llla inhibitors & $1.20(0.70$ to 2.11$)$ & 0.40 \\
Time-to-treatment subgroups & $0.80(0.60$ to 1.15$)$ & 0.10 \\
MVD & $0.80(0.50$ to 1.32$)$ & 0.41 \\
LAD as infarct-related artery & $0.32(0.21$ to 0.61$)$ & $<0.001$ \\
TIMI flow $0-1$ & $0.68(0.33$ to 1.43$)$ & 0.31 \\
TS & $1.21(1.00$ to 1.48$)$ & 0.05 \\
TA & $2.41(1.44$ to 4.00$)$ & 0.001 \\
RVD $\geq 4$ mm & $1.42(0.60$ to 3.01$)$ & 0.40 \\
Distal embolisation & $0.41(0.15$ to 1.32$)$ & 0.12
\end{tabular}

$L A D$, left anterior descending artery; MVD, multivessel disease; RVD, reference vessel diameter; TA, thrombus aspiration; TS, thrombus score. 
Table 7 Estimated associations in the final logistic regression model

\begin{tabular}{lll}
\hline & OR $(\mathbf{9 5} \%$ Cl) & p \\
\hline Age & $0.96(0.94$ to 0.99$)$ & 0.008 \\
Sex (M) & $0.76(0.34$ to 1.70$)$ & 0.50 \\
STUDY variable & & 0.009 \\
EXPORT vs REMEDIA & $0.60(0.26$ to 1.39$)$ & 0.24 \\
PIHRATE vs REMEDIA & $0.34(0.17$ to 0.68$)$ & 0.002 \\
Diabetes & $0.32(0.12$ to 0.86$)$ & 0.025 \\
Time-to-treatment subgroups & $0.40(0.20$ to 0.82$)$ & 0.01 \\
LAD as infarct-related artery & $0.30(0.16$ to 0.56$)$ & $<0.001$ \\
TS & $1.17(0.90$ to 1.51$)$ & 0.24 \\
TA & $0.49(0.10$ to 2.42$)$ & 0.38 \\
TA by TTT (interaction term) & $2.5(1.02$ to 6.26$)$ & 0.04 \\
\hline
\end{tabular}

LAD, left anterior descending artery; TA, thrombus aspiration; TS, thrombus score; TTT, time to treatment.

2 or 3) at presentation (table 1). However, in our study, we accounted for between-study differences in the statistical modelling and found no evidence of treatment effect heterogeneity ( $p$ value for interaction term between 'study variable' and 'thrombus aspiration variable' $=0.2$ ).

Another possible limitation is the use of two different TA devices in the included studies (Export catheter in the Noel study and Diver CE in the REMEDIA and PIHRATE trials; table 1), although no large difference in the effect size was previously observed between the two devices. ${ }^{28}$

The results may also have been influenced by the quality of each original trial. Indeed, no single-patient data were available on thienopyridine, or on the issue of direct stenting versus predilatation, or on drug-eluting stents use.

\section{Competing interests None.}

Patient consent Obtained.

Ethics approval This study was conducted with the approval of the ethics committee of the Catholic University of Sacred Heart, Rome, Italy.

Provenance and peer review Not commissioned; externally peer reviewed.

\section{REFERENCES}

1. Keeley EC, Boura JA, Grines CL. Primary angioplasty versus intravenous thrombolytic therapy for acute myocardial infarction: a quantitative review of 23 randomised trials. Lancet 2003;361:13-20.

2. Rezkalla SH, Kloner RA. No-reflow phenomenon. Circulation 2002;105:656-62.

3. van't Hof AW, Liem A, Suryapranata $H$, et al. Angiographic assessment of myocardial reperfusion in patients treated with primary angioplasty for acute myocardial infarction: myocardial blush grade. Zwolle Myocardial Infarction Study Group. Circulation 1998;97:2302-6.

4. Niccoli G, Burzotta F, Galiuto L, et al. Myocardial no-reflow in humans. J Am Coll Cardiol 2009;54:281-92.

5. Burzotta $\mathbf{F}$, Testa L, Giannico F, et al. Adjunctive devices in primary or rescue $\mathrm{PCl}$ : a meta-analysis of randomized trials. Int J Cardiol 2008:123:313-21.

6. Vlaar PJ, Svilaas T, van der Horst IC, et al. Cardiac death and reinfarction after 1 year in the Thrombus Aspiration during Percutaneous coronary intervention in Acute myocardial infarction Study (TAPAS): a 1-year follow-up study. Lancet 2008; 371:1915-20.

7. Burzotta F, De Vita M, Gu YL, et al. Clinical impact of thrombectomy in acute ST-elevation myocardial infarction: an individual patient-data pooled analysis of 11 trials. Eur Heart J 2009. (Epub ahead of print).
8. Reimer KA, Vander Heide RS, Richard VJ. Reperfusion in acute myocardial infarction: effect of timing and modulating factors in experimental models. Am J Cardiol 1993;72:13G-21G.

9. Reffelmann T, Hale SL, Li G, et al. Relationship between no reflow and infarct size as influenced by the duration of ischemia and reperfusion. Am J Physiol Heart Circ Physiol 2002;282:H766-72.

10. Nallamothu BK, Bradley EH, Krumholz HM. Time to treatment in primary percutaneous coronary intervention. N Engl J Med 2007;357:1631-8.

11. De Luca G, van't Hof AW, de Boer MJ, et al. Time-to-treatment significantly affects the extent of ST-segment resolution and myocardial blush in patients with acute myocardial infarction treated by primary angioplasty. Eur Heart $J$ 2004:25:1009-13.

12. De Luca G, Suryapranata H, Ottervanger JP, et al. Time delay to treatment and mortality in primary angioplasty for acute myocardial infarction: every minute of delay counts. Circulation 2004:109:1223-5.

13. Ikari $\mathbf{Y}$, Sakurada M, Kozuma K, et al. VAMPIRE Investigators. Upfront thrombus aspiration in primary coronary intervention for patients with ST-segment elevation acute myocardial infarction. Report of the VAMPIRE (VAcuuM asPlration thrombus REmoval) Trial. J Am Coll Cardiol Intv 2008;1:424-31.

14. Chao CL, Hung CS, Lin YH, et al. Time-dependent benefit of initial thrombosuction on myocardial reperfusion in primary percutaneous coronary intervention. Int J Clin Pract 2008:62:555-61.

15. Burzotta F, Trani C, Romagnoli E, et al. Manual thrombus-aspiration improves myocardial reperfusion: the randomized evaluation of the effect of mechanical reduction of distal embolization by thrombus-aspiration in primary and rescue angioplasty (REMEDIA) trial. J Am Coll Cardiol 2005;46:371-6.

16. Dudek D. Polish-Italian-Hungarian Randomized Thrombus-aspiration Trial. PHIRATE trial; Expert slide presentation from Late Breaking Clinical Trials. TCT 2007.

17. Noel B, Morice MC, Lefevre T, et al. Thrombus aspiration in acute ST-elevation myocardial infarction: a randomized controlled trial. Circulation 2005:112(Suppl II):519.

18. TIMI: TIMI Study Group. The Thrombolysis in Myocardial Infarction (TIMI) trial. N Engl J Med 1985:312(Suppl):932-6.

19. Gibson CM, de Lemos JA, Murphy SA, et al. TIMI Study Group. Combination therapy with abciximab reduces angiographically evident thrombus in acute myocardial infarction: a TIMI 14 substudy. Circulation 2001: 103:2550-4.

20. van't Hof AW, Liem A, Suryapranata $H$, et al. Angiographic assessment of myocardial reperfusion in patients treated with primary angioplasty for acute myocardial infarction: myocardial blush grade. Zwolle Myocardial Infarction Study Group. Circulation 1998;97:2302-6.

21. van't Hof AW, Liem A, de Boer MJ, et al. Clinical value of 12-lead electrocardiogram after successful reperfusion therapy for acute myocardial infarction. Zwolle Myocardial infarction Study Group. Lancet 1997;350:615-19.

22. Sorajja P, Gersh BJ, Costantini C, et al. Combined prognostic utility of ST-segment recovery and myocardial blush after primary percutaneous coronary intervention in acute myocardial infarction. Eur Heart J 2005;26:667-74.

23. Reffelmann T, Kloner RA. The no-reflow phenomenon: A basic mechanism of myocardial ischemia and reperfusion. Basic Res Cardiol 2006;101:359-72.

24. Ambrosio G, Weisman HF, Mannisi JA, et al. Progressive impairment of regional myocardial perfusion after initial restoration of postischemic blood flow. Circulation 1989;80:1846-61.

25. Tranum-Jensen J, Janse MJ, Fiolet WT, et al. Tissue osmolality, cell swelling, and reperfusion in acute regional myocardial ischemia in the isolated porcine. Circ Res 1981:49:364-81.

26. Burzotta F, Crea F. Thrombus-aspiration: a victory in the war against no reflow. Lancet 2008;37:1889-90.

27. Kushner FG, Hand M, Smith SC Jr, et al. 2009 focused updates: ACC/AHA guidelines for the management of patients with ST-elevation myocardial infarction (updating the 2004 guideline and 2007 focused update) and ACC/AHA/SCAI guidelines on percutaneous coronary intervention (updating the 2005 guideline and 2007 focused update) a report of the American College of Cardiology Foundation/ American Heart Association Task Force on Practice Guidelines. J Am Coll Cardiol 2009:54:2205-41.

28. Vlaar PJ, Svilaas $\mathrm{T}$, Vogelzang $\mathrm{M}$, et al. A comparison of 2 thrombus aspiration devices with histopathological analysis of retrieved material in patients presenting with ST-segment elevation myocardial infarction. JACC Cardiovasc Interv 2008;1:258-64. 